\title{
Sınıf Öğretmeni Adaylarının Medya Okur-Yazarlık Düzeylerinin İncelenmesi
}

\author{
Firat SARSAR ${ }^{1}$ Gizem ENGIN ${ }^{2}$
}

Geliş Tarihi: 17.02.2015 Kabul Tarihi: 11.03.2015

Öz

$\mathrm{Bu}$ araştırmanın temel amacı, öğretmen adaylarının medya okur-yazarlık düzeylerini cinsiyet, gazete ve dergileri takip etme ve sosyal medya hesabı kullanım durumuna göre incelemektir. $\mathrm{Bu}$ araştırmanın çalışma grubunu, kolay ulaşılabilir olması sebebiyle seçilen 2014-2015 öğretim yılında Ege Üniversitesi Eğitim Fakültesi'nde öğrenim gören Sınıf Öğretmenliği Lisans programındaki toplam 188 öğretmen adayı oluşturmaktadır. Çalışmada veriler, Korkmaz ve Yeşil (2011) tarafından geliştirilen "Medya ve Televizyon Okuryazarlık Düzeyleri Ölçeği”" ile toplanmıştır. Araştırma sonuçlarına göre, cinsiyet ve sosyal medya hesabı kullanımı açısından alt boyutlarda anlamlı farklılaşma bulunmuştur. Gazete ve dergi kullanımının düzenli oluşu okuryazarlık alt boyutunda düzenli takip yapanlar lehine anlamlı farklılık oluşturmuş, bağımlılık alt boyutunda ise anlamlı farklılık oluşturmamıştır.

Anahtar Kelimeler: Medya okuryazarlığı, öğretmen adayları, eğitim fakültesi, televizyon okuryazarlığı, sınıf öğretmeni

\footnotetext{
${ }^{1}$ Dr, Ege Üniversitesi Eğitim Fakültesi, Bilgisayar ve Öğretim Teknolojileri Eğitimi

${ }^{2}$ Dr, Ege Üniversitesi Eğitim Fakültesi, Sınıf Öğretmenliği
} 


\title{
Investigation of The Media Literacy Level of Primary School Teacher Candidates
}

Submitted by 17.02.2015 Accepted by 11.03.2015

\begin{abstract}
Media literacy is to understand the messages which are given via media tool and react after analyzing and evaluating the messages. It is critical to know how to teach media literacy. Therefore, this study aims to investigate the level of pre-school teachers' media literacy level. This study also seeks to understand relations between media literacy and the frequency of watching TV, reading newsletter and having internet connection. Current study was conducted with 188 pre-school teachers at Ege University during fall semester in 2014-2015 academic year. The Media and TV Literacy Level Survey created by Korkmaz and Yeşil (2011) was carried out. According to results of the current study, there is no significant different between gender and Media Literacy as well as between social media and Media Literacy. There is a significant difference between the participants who follow the magazines/newsletters regularly and Media Literacy, and no significant difference between the participants who follow the magazines/newsletters regularly and addiction.
\end{abstract}

Key Words: Media literacy, teacher candidate, faculty of education, television literacy, primary school teacher 


\section{Giriş}

Günümüzde görsel ve işitsel paylaşım yolları olağanüstü bir artış göstermiştir. Birey bu paylaşım yolları aracılığıyla bilgiye erişimde neredeyse hiç zorluk yaşamamaktadır. Bireyin medya kanalları aracılığıyla mesajı alan alıcı rolünün yanına, sahip oldukları medya hesapları yoluyla kendi iletilerini veya mesajlarını paylaşımlarına olanak sağlayan kaynak rolü de eklenmiştir. Bireylerin rollerindeki bu değişim kolaylaştırıcı ve etkileyici olduğu kadar tedirgin edici de olabilmektedir. Bu tedirginliğin etkili medya okur-yazarı sayısının artışı ile azaltılabileceğine inanılmaktadır.

21. yüzyılda bireyler bilgi ve iletişim teknolojileri sayesinde ulaşılan ve seçkisiz sunulan mesajlara karşı temkinli olmak durumundadır. Bireyler mesajla karşı karşıya kaldıklarında doğruluğunu araştırmalı, analiz etmeli, eleştirel yaklaşmalı ve bu bilgiyi kendileri yapılandırmalıdırlar. Çünkü bilgiye ulaşmak, hangi bilginin doğru ve gerekli olduğunu anlamak adına yeterli olmamaktadır. Bireylerin sahip olması gereken medya okuryazarlığı gibi bazı okur-yazarlıkların gündeme gelme sebepleri arasında bunlar görülebilir (Som ve Kurt, 2012). Medyanın toplum üzerindeki büyük etkisini görmemek mümkün değildir. Özellikle kitle iletişim araçları aracılığıyla medya ekonomik, toplumsal, siyasal, kültürel alanda küçümsenemeyecek etkiler yaratmakta toplumsal değişim sürecinin baş aktörü olarak görülmektedir (Elma, Kesten, Dicle ve Uzun, 2010). Potter (2010) da bu görüşü destekleyerek medyanın günümüzde toplumsal yaşamı belirleyen en önemli merkezlerden biri olduğunu ifade etmiştir. Medya araçları vasıtasıyla gerçekleşen iletişim hızla artmıştır ve artmaktadır. Medya, insanların sosyalleşmesinde, haber ve eğitim almasında hatta eğlenmesinde aktif rol almaktadır. Hayatın neredeyse her alanını etkileyen medyadan doğru faydalanmak, bireyin hangi biçimde medyaya maruz kaldığını anlama ve karşılaştığı iletileri yorumlama becerisini kazanması, medya okur-yazarlığını kazanmış olmasına bağlıdır (Potter, 2010).

Etkili bir medya okur-yazarı olmanın ölçütleri alanyazından farklı araştırmacılar tarafından ele alınmıştır. Ancak etkili medya okur-yazarı olmanın ölçütleri hakkında genel bilgi vermeden önce “medya okur-yazarı olmak nedir?” onu tanımlamanın problemin çözümünde daha katkı sağlayıcı olduğuna inanılmaktadır. Medya okur-yazarlığı yeni bir terim olmamakla birlikte son 20 yılda çok gelişme kaydetmiş ve popülerlik kazanmıştır (Lee ve So, 2014). Andrew ve Durran (2007) medya okur-yazarlığını tanımlarken üç ana özelliği vurgulamışlardır. Bu özellikler; kültürellik, kritiklik ve yaratıcılıktır. Bu özellikleri sınıflarken bunların aynı zamanda medya okur-yazarlığının da özellikleri olduğunu belirtmişlerdir. Potter 
(2010) ise terimsel ve anlamsal olarak medya okur-yazarlığının birçok alana göre başka şekillendiğini belirtmiş ve kendi makalesinde bazı tanımlara yer vermiştir.

Medya okur-yazarlığının en kapsamlı tanımı; geniş ve değişik iletişim mesajlarına ulaşabilme, analiz edebilme, üretme ve değerlendirme olarak yapılabilir (Aufderheide ve Firestone, 1993). Bireylerin iyi bir medya okur-yazarı olmaları Andrew ve Durran'1n (2007) da bahsetmiş olduğu kültürellik, kritiklik ve yaratıcılık özelliklerine sahip olması beklenilmektedir. Başka bir deyişle, iletişim mesajlarına ulaşabilmenin kültürel bir bağlamı olduğu gibi analiz etmenin kritik yapma özelliğiyle doğrudan bağlantısı vardır. Tanımda yer alan değerlendirme öğesinin ise yaratıcılıkla bağlantılı olması gerekmektedir. Bununla birlikte, Adrew ve Durran (2007) tarafindan belirtilen özellikler Aufderheide ve Firestone (1993) yapmış olduğu tanım içindeki her bir duruma karşılık geleceği gibi birden fazla durum için de ilişkilendirilebilecek bir yapıya sahiptir. Daha geniş bir anlatımla, bir medya aracını ya da araçlarını seçme durumu kültürel bir durum olabileceği gibi kritik yapmayı gerektiren bir durum da olabilir. Örnek olarak, televizyon seyretmek bir kültür olsa da hangi kanalı ya da kanalları izlemeyeceğini seçme kritik yapma becerisini gerektirmektedir. Bu özelliklerin kazanılması için bireyin iyi bir eğitim sürecinden geçmesi daha etkili bir medya okur-yazarı olması açısından önemli görülmektedir.

Medya okur-yazarlık düzeyi düşük olan bireyler için görsel-işitsel paylaşımda yaşanan yoğunluk istenmeyen durumlara sebep olabilir. Birey doğru okuma biçimleri geliştiremediyse bu paylaşımlar onun sömürülmesine ya da yanlış yönlendirilmesine neden olabilir. Bu gibi istenmeyen durumların önüne geçmek için bireye medya okur-yazarlığına yönelik bir eğitim verilmesi uygun olacaktır (Gül, 2013).

Yalvaç (2012), medya okur-yazarlığının iki temel yapıdan oluştuğunu belirtmektedir. Bunlardan "ilkini medyadaki içeriğe doğru, hızlı, etkin, verimli ve ekonomik erişebilmek için gerekli bilgi ve beceri (bilgi okur-yazarlığı, teknoloji kullanımı vd.); ikincisini ise medya içeriğini doğru ve tam anlama ve aynı zamanda bu içeriği sorgulayarak/eleştirerek araştırabilme, değerlendirebilme, kullanma yeteneği” olarak açıklamıştır (Yalvaç, 2012, s.1). Kurt ve Dürüm (2010) de bireylerin medyadan doğru faydalanabilmeleri için daha eleştirel tüketici olmaları gerektiğini ifade etmekte ve bunun için birtakım becerilere gereksinim duyacaklarını savunmaktadır. Yeni iletişim teknolojileri bireylerin hayatlarında lüks olmaktan çok birer ihtiyaç haline gelmektedir. $\mathrm{Bu}$ durum ise kullanıcı sayısını arttırdı̆̆ gibi kullanıcıların oluşturduğu yazılı veya yazılı olmayan mesajları da arttırmaktadır. Çünkü bireyler artık bilgiye birçok kaynaktan ulaşabilmekte, aynı zamanda bu kaynakları amaçları 
doğrultusunda da kullanabilmektedir. Bu durum ise bilginin doğruluğu konusunda kaygıları arttırdığı gibi eleştirmeden ve kritik yapmadan bu bilgileri kullanan bireyleri de yanlış yönlendirmektedir. $\mathrm{Bu}$ nedenle bireylerin erken yaşlarda medya okur-yazarlık becerilerini arttırmak ve yeni medya araçlarına karşı farkındalık oluşturmak gerekmektedir.

Toplumların ve bireylerin davranışlarını şekillendiren önemli güçlerden biri medyadır. Toplumun geleceğini ellerinde tutan öğretmenlerin eğitimlerinde öğretmen ve öğrencilere eleştirel düşünme becerisi kazandıracak ve yeni öğrenme yolları sunacak olan medya okuryazarlığının yer alması gerekmektedir (Schwarz, 2003). Tüzel ve Tok (2013), çağın olanaklarının bireylere sunduğu bilgisayar ya da akıllı telefonlar aracılığıyla çok uzaktaki birine mesaj atmak, bir tuşa basarak kilometrelerce uzağa mesajını e-posta ile göndermek ya da almak, kafasında soru işareti oluşturan bir konuyu anında araştırmak, bir kütüphane dolusu kitabı bir telefonda ya da bilgisayarda taşıyabilmek gibi imkanlardan bahsetmiş tüm bu gelişmelerin toplumları siyasî, ekonomik ve kültürel açıdan da etkilediğini veya değiştirdiğini belirtmiştir. Eğitim, hayata hazırlayıcı rolü üstlendiğine göre bu değişime bireyleri hazırlayacak bir eğitim anlayışının benimsenmesi gerekir (Tüzel ve Tok, 2013). Bu eğitimin içinde yer alması gereken medya okur-yazarlığı için eğitime hizmet eden tüm paydaşların, süreçteki deneyimlerini, tekniklerini ve felsefelerini paylaşma olanakları ve eğitimle ilgili bu deneyimlerini ölçmek ve değerlendirmek için arayış içinde olmaları gerekmektedir (Hobbs, 2004). Çünkü bilgi teknolojileri ve teknoloji destekli öğretim ortamlarının eğitim sisteminde kullanımı her geçen gün artmaktadır. Bu sebeple öğretmenlerin ve öğretmen adaylarının medya okur-yazarı ve teknoloji kullanım bilgisine sahip olarak yetiştirilmesi önemli bulunmaktadır. Özellikle, öğretmen adaylarının teknolojiye yönelik bilgilendirilmesi ve kavram yanılgıları varsa bunların düzeltilmesi bu sürecin sağlıklı işlemesine yardımcı olacaktır (Çoşkun vd., 2013). Öğretmenlerin etki alanlarının genişliği düşünüldüğünde yetiştirecekleri nesilleri güncel ve anlamlı bilgilerle desteklemeleri büyük önem taşımaktadır. Keza yeni nesil medya araçlarının çok yoğun kullanıldığı bir ortamda dünyaya gelmekte ve dijital birer vatandaş olmaktadır. Bu nedenle bu süreç etkili ve temkinli bir şekilde kontrol edilmelidir.

$\mathrm{Bu}$ araştırmada öğretmen adaylarının medya okur-yazarlık düzeyleri ile cinsiyet, düzenli gazete takip etme, düzenli dergi takip etme, sosyal medya kullanımı arasındaki ilişkilerin incelenmesi amaçlanmıştır. Bu amaçla aşağıdaki sorulara yanıt aranmıştır.

Öğretmen adaylarının medya ve televizyon okur-yazarlık düzeyleri;

a) cinsiyete göre, 
b) düzenli gazete takibine göre,

c) düzenli dergi takibine göre,

d) sosyal medya hesabı kullanımına göre farlılık göstermekte midir?

\section{Yöntem}

$\mathrm{Bu}$ çalışma bir durum saptamasını içerdiğinden betimsel araştırma modeli çerçevesinde kurgulanmıştır. Bu kapsamda öğretmen adaylarının medya ve televizyon okur-yazarlık düzeyleri, cinsiyete, düzenli gazete takibine, düzenli dergi takibine ve sosyal medya hesab1 kullanımına göre ilişkisine bakılmıştır. Araştırmanın örneklemini Ege Üniversitesi Eğitim Fakültesi Sınıf Öğretmenliği Lisans programında öğrenim gören 188 öğretmen adayı oluşturmaktadır. Ege Üniversitesi Eğitim Fakültesi Sınıf Öğretmenliği Lisans programında öğrenim gören katılımcılarla sürdürülmesinin sebebi kolay ulaşılabilir olmasıdır. Araştırmanın evrenini Ege Üniversitesi Eğitim Fakültesinin öğrencileri oluşturmaktadır.

\section{Veri Toplama Araçları}

Araştırmada Korkmaz ve Yeşil (2011) tarafindan geliştirilen "Medya ve Televizyon Okuryazarlık Düzeyleri Ölçeği” veri toplama amacı ile kullanılmıştır. Ölçeğin yapı geçerliğini test etmek üzere veriler üzerinde ilk olarak Kaiser-Meyer-Oklin (KMO) ve Bartlett test analizleri yapılmış ve $\mathrm{KMO}=0,923$; Bartlett testi değeri ise $\mathrm{x} 2=5106,959 ; \mathrm{sd}=190(\mathrm{p}=0,000)$ olarak belirlenmiştir. $\mathrm{Bu}$ değerler çerçevesinde, 20 maddelik ölçek üzerinde faktör analizi yapılabileceği anlaşıldıktan sonra Varimax dik döndürme tekniği uygulanarak ölçeğin birbirinden ilişkisiz faktörlere ayrışıp ayrışmadığını görülüş ve faktör yükleri de incelenmiştir. 20 madde içinde yer alan fakat madde yükü 0,30'un altında olan 2 madde ölçekten çıkarıldıktan sonra geriye kalan maddeler üzerinde faktör analizi işlemi tekrarlanmıştır. $\mathrm{Bu}$ işlem sonrasında ölçek beş basamaklı likert tipi bir ölçek olup 18 maddeden oluşan nihai halini almıştır. Bu maddeler okur-yazarlık (13 madde) ve bağımlılık (5madde) olmak üzere iki faktör altında toplanmıştır. Ölçeğin faktörlere göre Cronbach alpha güvenirlik katsayıları okur-yazarlık için 0,914 ve bağımlılık için 0,851 olarak hesaplanmıştır. Ölçeği geliştiren araştırmacılar faktörlerdeki madde sayıları eşit olmadığı için ham puanları, en düşüğü 20, en yükseği ise 100 puan olacak şekilde standart puanlara dönüştürülmesinin uygun olacağını belirtmişler, bu işlem için Xstandart puan= Xhampuan / ÖlçMad Say x20 formülünü kullanmayı önermişlerdir. 


\section{Verilerin Analizi}

Ölçekten elde edilen veriler veri toplama araçları başlığı altında verilen ve ölçeği geliştiren araştırmacılar tarafından önerilen formüle göre düzenlendikten sonra cinsiyet, düzenli gazete okuma, düzenli dergi okuma ve sosyal medya hesabı kullanımına göre incelenmiştir. Analizlerde SPSS istatistik programı kullanılmış ve sosyal medya hesabı kullanımı değişkeni için Mann Whitney U testi (grupların birinin eleman sayısı 30'dan küçük olduğu gerekçesiyle), diğer tüm değişkenler için ise t-testi uygulanmıştır.

\section{Bulgular}

$\mathrm{Bu}$ bölümde araştırma sorularını yanıtlamak amacıyla toplanan verilerin istatistiksel bulgularına yer verilecektir.

Tablo 1. Medya ve Televizyon Okur-yazarlık Düzeyleri Ölçek Alt Boyut Puanlarının Cinsiyete Göre T-Testi Sonuçları

\begin{tabular}{cccccccc}
\hline Okur-yazarlık & Cinsiyet & $\mathrm{N}$ & $\mathrm{X}$ & $\mathrm{S}$ & $\mathrm{Sd}$ & $\mathrm{t}$ & $\mathrm{P}$ \\
\hline \multirow{3}{*}{ Bağımlılık } & Kadın & 148 & 79.67 & 8.52 & 186 & -.601 & .548 \\
& Erkek & 40 & 80.57 & 7.89 & & & \\
\cline { 2 - 7 } & Kadın & 148 & 39.21 & 15.61 & 186 & .429 & .668 \\
& Erkek & 40 & 38.00 & 16.89 & & & \\
\hline
\end{tabular}

“Öğretmen Adaylarının Medya ve Televizyon Okur-yazarlığı Ölçeği”nin okuryazarlık ve bağımlılık faktörlerinde cinsiyete göre anlamlı farklılaşma olup olmadığını tespit etmek amaciyla uygulanan t-testi sonuçları Tablo.1'de verilmiştir. Uygulanan t-testi sonucuna göre cinsiyet değişkenine göre okur-yazarlık ve bağımlılık alt boyutunda anlamlı bir farklılaşma tespit edilmemiştir.

Tablo 2.Medya ve Televizyon Okur-yazarlık Düzeyleri Ölçek Alt Boyut Puanlarının Düzenli Gazete Takip Edip Etmeme Durumuna Göre T-Testi Sonuçları

\begin{tabular}{llllllll}
\hline \multirow{3}{*}{ Okur-yazarlık } & Takip & $\mathrm{N}$ & $\mathrm{X}$ & $\mathrm{S}$ & $\mathrm{Sd}$ & $\mathrm{t}$ & $\mathrm{P}$ \\
\cline { 2 - 8 } & Eden & 57 & 83.04 & 7.50 & 186 & 3.53 & .001 \\
\multirow{3}{*}{ Bağımlılık } & Etmeyen & 131 & 78.48 & 8.38 & & & \\
\cline { 2 - 8 } & Eden & 57 & 35.78 & 14.37 & 186 & -1.81 & .71 \\
& Etmeyen & 131 & 40.33 & 16.32 & & & \\
\hline
\end{tabular}


“Öğretmen Adaylarının Medya ve Televizyon Okur-yazarlığı Ölçeği”nin okuryazarlık ve bağımlılık faktörlerinde düzenli gazete takip edip etmeme durumuna göre anlamlı farklılaşma olup olmadığını tespit etmek amacıyla uygulanan t-testi sonuçları Tablo.2'de verilmiştir. Uygulanan t-testi sonucuna göre gazete takibi değişkenine göre okur-yazarlık alt boyutunda gazete takip edenler lehine anlamlı bir farklılaşma tespit edilmiştir. Bağımlılık alt boyutunda ise gazete takibi değişkenine göre anlamlı bir farklılık bulunmamıştır. Ancak gazete takibi düzenli olan öğretmen adaylarının bağımlılık düzeylerinin istatistiki farklılık yaratmayacak şekilde düşük olduğu görülmektedir.

Tablo 3. Medya ve Televizyon Okur-yazarlık Düzeyleri Ölçek Alt Boyut Puanlarının Düzenli Dergi Takip Edip Etmeme Durumuna Göre T-Testi Sonuçları

\begin{tabular}{llllllll}
\hline \multirow{3}{*}{ Okur-yazarlık } & Takip & $\mathrm{N}$ & $\mathrm{X}$ & $\mathrm{S}$ & $\mathrm{Sd}$ & $\mathrm{t}$ & $\mathrm{p}$ \\
\cline { 2 - 8 } & Eden & 33 & 84.05 & 7.48 & 186 & 3.24 & .001 \\
\multirow{3}{*}{ Bağımlılık } & Etmeyen & 155 & 78.97 & 8.30 & & & \\
\cline { 2 - 8 } & Eden & 33 & 37.21 & 17.67 & 186 & -.69 & .448 \\
& Etmeyen & 155 & 39.32 & 15.47 & & & \\
\hline
\end{tabular}

“Öğretmen Adaylarının Medya ve Televizyon Okur-yazarlığı Ölçeği”nin okuryazarlık ve bağımlılık faktörlerinde düzenli dergi takip edip etmeme durumuna göre anlamlı farklılaşma olup olmadığını tespit etmek amacıyla uygulanan t-testi sonuçları Tablo.3'te verilmiştir. Uygulanan t-testi sonucuna göre dergi takibi değişkenine göre okur-yazarlık alt boyutunda dergi takip edenler lehine anlamlı bir farklılaşma tespit edilmiştir. Bağımlılık alt boyutunda ise, dergi takibi değişkenine göre anlamlı bir farklılık bulunmamıştır.

“Öğretmen Adaylarının Medya ve Televizyon Okur-yazarlığı Ölçeği”nin okuryazarlık ve bağımlılık faktörlerinde sosyal medya hesabı kullanım durumuna göre anlamlı farklılaşma olup olmadığını tespit etmek amacıyla uygulanan Mann Whitney U sonuçları Tablo.4'te verilmiştir. Uygulanan Mann Whitney U Testi sonucuna göre sosyal medya hesabı kullanım durumu okur-yazarlık ve bağımlılık alt boyutları için anlamlı farklılık yaratmamaktadir. 
Tablo 4.Medya ve Televizyon Okur-yazarlık Düzeyleri Ölçek Alt Boyut Puanlarının Sosyal Medya Hesabı Kullanım Durumuna Göre MannWhitney U Testi Sonuçları

\begin{tabular}{llllll}
\hline Okur-yazarlık & $\mathrm{N}$ & $\begin{array}{l}\text { Sira } \\
\text { Ortalaması }\end{array}$ & Sira Toplamı & $\mathrm{U}$ & $\mathrm{p}$ \\
\hline Kullanan & 178 & 94.26 & 16777.50 & 846.50 & .795 \\
Kullanmayan & 10 & 98.85 & 988.50 & & \\
\hline & & Sira & & \\
Bağımlılık & $\mathrm{N}$ & Ortalaması & Sira Toplamı & $\mathrm{U}$ & $\mathrm{p}$ \\
\hline Kullanan & 178 & 93.13 & 16576.50 & 645.50 & .142 \\
Kullanmayan & 10 & 118.95 & 1189.50 & & \\
\hline
\end{tabular}

\section{Sonuç ve Tartışma}

$\mathrm{Bu}$ araştırma Ege Üniversitesi Eğitim Fakültesi Sınıf Öğretmenliği Lisans programında öğrenim görmekte olan 188 öğretmen adayı ile yürütülmüştür. Çalışmanın sonuçları dikkatli bir şekilde incelendiğinde, cinsiyet faktörünün Medya ve Televizyon Okur-yazarlığı üzerinde bir etkisi olmadığı gözlenmiştir. Bu sonuç Som ve Kurt (2012) tarafından yapılan çalışma ile benzerlik göstermektedir. Bu durum medya iletişim araçlarına herkes tarafından ulaşılabilir olmasiyla yorumlanabilir.

Araştırma sonunda ortaya çıkan bir diğer bulguya göre, gazete ve dergileri düzenli takip etme medya ve televizyon okur-yazarlığı ölçeğinin okur-yazarlık alt boyutunda düzenli takip edenler lehine anlamlı farklılaşma yaratmaktadır. $\mathrm{Bu}$ sonuç, Karaman ve Karataş (2009)'ın yaptıkları araştırmada düzenli gazete takibinin medya okur-yazarlığını olumlu bir şekilde etkilediği bulgusuyla örtüşmektedir. Bağımlılık faktöründe ise gazete ve dergileri düzenli takip etmenin anlamlı farklılaşma doğurmadığı gözlenmiştir. Aslında bu sonuç şaşırtıcı değildir. Medya ve televizyon okur-yazarlık düzeyinin seçme, yorumlama, analiz etme ve tepki oluşturma gibi eylemleri içerdiği düşünülürse medyadan yararlanmanın bilinçli olması gerekliliğinin farkına varma ile ilişkili olduğu görülebilir. Vurucu olan nokta okuryazarlık düzeyi arttıkça bağımlılık düzeyinin azalmasıdır (Korkmaz ve Yeşil, 2011). Bu durum okur-yazarlık durumu ile bilincin ilişkili olduğu görüşünü destekler niteliktedir.

Araştırmada sosyal medya hesabı kullanımının medya ve televizyon okur-yazarlık bağımlılık düzeyi üzerinde anlamlı farklılaşmaya sebep olup olmadığına da bakılmış ve anlamlı farklılık oluşturmadığı sonucuna ulaşılmıştır. Bu sonuç, gazete ve dergileri düzenli 
takip etme değişkenleri için yapılan yorumu destekler niteliktedir. Karaman ve Karataş'ın (2009) internet erişimi ve kullanım sıklığı medya okur-yazarlık düzeyini etkilemekte ve artırmaktadır sonucunun aksine, internet üzerinden sosyal medya hesaplarını kullanan bireylerin önceliği, sosyal medya hesabı kullanan arkadaşlarını takip etmek olabilir (Sarsar ve Harmon, 2011; 2012, Engin ve Sarsar, 2015). Ancak, Karaman'ın (2010) yapmış olduğu araştırmada belirttiği gibi internetin bilgiye ulaşmada en kısa ve hızlı yol olarak görüldüğü gerçeği de unutulmamalıdır. Öğrenilen yanlış bilgi bir mesaj olarak karşı tarafa çok hızlı aktarılabileceği gibi bu bilginin doğruluğuna inanan geniş bir kitlenin oluşabilecek olması da kaygı verici görülmektedir. Filiz ve Fisun’un (2012) çalışmasının sonucuna göre ise öğretmen adaylarının medya dendiğinde ilk akıllarına gelen araç televizyon olarak ifade edilmiş, internet ise ikici sırada yer almıştır. Bu sonuçta göstermektedir ki öğretmen adayları medya iletilerini internetten daha çok televizyonla takip etmektedir.

Medya okur-yazarlığı eğitimin temelinde bilinçli medya kullanıcıları yetiştirmek esas alınmıştır. Bu nedenle öğretmen eğitiminde, medya okur-yazarlığının önemi gün geçtikçe artmaktadır. Bu konuda Radyo Televizyon ve Üst Kurulu (RTÜK) geniş kapsamlı çalışmalar yapmakta ve konu hakkında çeşitli kurum ve kuruluşlarca yapılan çalışmaları http://www.medyaokuryazarligi.org.tr/ internet sitesinde paylaşmaktadır. $\mathrm{Bu}$ çalışmaları öğretmenlerin ve öğrencilerin yanı sıra yetişkinlerin ve medya çalışanlarının hizmetine sunmaktadır (Rtük, 2015). Bununla birlikte, Milli Eğitim Bakanlığının, Ortaokul ve İmam Hatip Ortaokulu Medya Okur-yazarlığı Dersi Öğretim Programının genel amaçlarında; öğrencilerin medya kanallarından doğru bilgiyi seçebilmesi, yorumlayabilmesi, değerlendirmesi ve öğrencinin kendine ait özgün ileti oluşturabilmesi açıcça belirtilmiştir (TTKB, 2013). Bu durumun oluşabilmesi içinse aynı özellikleri taşıyan öğretmen adaylarının da yetiştirilmesi gerekmekte olup (Kurt ve Kürüm, 2010), öğretmen yetiştiren kurumların programlarında medya okur-yazarlığı ders halinde eklenmelidir (Deveci ve Çengelci, 2008; Filiz ve Fisun, 2012). Bazı anabilim dallarında seçmeli ders olarak açılsa da bu dersi tüm anabilim dallarında öğrenim gören öğretmen adaylarının almasının daha uygun olacağı düşünülmektedir. 


\section{Kaynakça}

Andrew, B. ve Durran, J. (2007). Media literacy in schools: Practice, production and progression (1st ed.). Thousand Oaks, CA: SAGE Publications.

Aufderheide P. ve Firestone, C. (1993) Media literacy: A report of the national leadership conference on media literacy. Queenstown, MD: Aspen Institute

Deveci, H ve Çengelci, A. G. T. (2008). Sosyal bilgiler öğretmen adaylarından medya okuryazarlığına bir bakış. Yüzüncü Yıl Ünıversıtesı Ĕgıtım Fakültesi Dergisi, 5(2).

Elma, C., Kesten, A., Dicle, A.N. ve Uzun, E. M. (2010). Türkiye’de medya okuryazarlığ eğitimi: medyanın işleyişi ve etik ilkeler açısından bir değerlendirme. Kuram ve Uygulamada Eğitim Bilimleri / Educational Sciences: Theory \& Practice, 10 (3), 1409-1458.

Engin, G. ve Sarsar, F. (2015). Sınıf öğretmeni adaylarının küresel vatandaşlık düzeylerinin incelenmesi. International Journal of Human Sciences, 12(1), 150-161.

Filiz, Y. ve Fisun, A. (2012). Social studies teacher candidates' perceptions about media literacy. Procedia-Social and Behavioral Sciences, 46, 4897-4901.

Gül, A. A. (2013). Avrupa birliği'nde medya okuryazarlığı: düzenleme ve çalışmalarda gözlemlenen eğilimler. AJIT-e: Online Academic Journal of Information Technology . 4 (11) ,15-33.

Karaman, M. K. (2010). Öğretmen adaylarının tv ve internet teknolojilerini kullanma amaç ve beklentilerinin medya okuryazarlığ $\breve{1}$ bağlamında değerlendirilmesi. Uşak Üniversitesi Sosyal Bilimler Dergisi ,2010 (6), 51-62.

Karaman, M. K. ve Karataş, A. (2009). Öğretmen adaylarının medya okuryazarlık düzeyleri. Ilköğretim Online, 8 (3), 798-808.

Korkmaz, Ö. ve Yeşil, R. (2011). Medya ve televizyon okuryazarlık düzeyleri ölçeği geçerlilik ve güvenirlik çalışması. Uluslararası Insan Bilimleri Dergisi, 8 (2), 110 126.

Kurt, A. A. ve Kürüm, D. (2010). Medya okuryazarlığı ve eleştirel düşünme arasındaki ilişki: Kavramsal bir bakış. Mehmet Akif Ersoy Üniversitesi Sosyal Bilimler Enstitüsü Dergisi, (2), 20-34.

Lee, A. Y. L. ve So, C. Y. K. (2014). Media literacy and information literacy: Similarities and differences. Comunicar, 21(42).

Potter, W. J. (2010). The state of media literacy. Journal of Broadcasting \& Electronic Media, 54(4), 675-696.

Sarsar, F. ve Harmon, S. (2011). Facebook as an online learning environment: Perceptions of undergraduate students. Proceedings in Society for Information Technology \& Teacher Education International Conference (1), 715-720

Sarsar, F. ve Harmon, S. W. (2012). Facebook as a learning environment (FOLE): Graduate students'perspectives. Proceedings in Society for Information Technology \& Teacher Education International Conference (1), 3759-3763

Schwarz, G. (2003). Renewing the humanities through media literacy. Journal of Curriculum and Supervision. 19(1), 44-53.

Som, S. ve Kurt, A. A. (2012). Bilgisayar ve öğretim teknolojileri eğitimi bölümü öğrencilerinin medya okuryazarlık düzeyleri. Anadolu Journal of Educational Sciences International. 2(1),104-119.

TTKB (2013), Ortaokul ve imam hatip ortaokulu medya okuryazarlığı öğretim programı, erişim: http:/ttkb.meb.gov.tr/www/ogretim-programlari/icerik/72 Erişim Tarihi: 15.10.2014

Tüzel, S. ve Tok, M. (2013). Öğretmen adaylarının dijital yazma deneyimlerinin incelenmesi. Tarih Okulu Dergisi. 6(15), 577-596. 
Ege Eğitim Dergisi 2015 (16) 1: 165-176

Sınıf Öğretmeni Adaylarının Medya Okur-Yazarlık Düzeylerinin İncelenmesi

Yalvaç, M. (2012). Bilginin Gücü. Haberdar Gazetesi. Erişim: http://www.neu.edu.tr/docs/byam/byam_(3).pdf 